\title{
The Effect of Adenosine Transport Inhibition on Cardiovascular Function and Survival after Severe Asphyxia in Fetal Lambs
}

\author{
HARMEN H. DE HAAN, JELTE DE HAAN, JOS L. H. VAN REEMPTS, HERMAN VAN BELLE, \\ AND TOM H. M. HASAART \\ Department of Obstetrics and Gynecology: University Hospital, Maastricht, The Netherlands /H.H.d.H., J.d.H., \\ T.H.M.H.J: and the Department of Life Sciences [J.L.H.I.R.J and Biochemistry /H.I.B.J, Janssen Research \\ Foundation, Beerse, Belgium
}

\begin{abstract}
When the energy demand exceeds the energy supply, anaerobic metabolism takes over and the ATP catabolite adenosine is generated. Adenosine acts as a coronary vasodilator, thereby increasing the oxygen supply to the heart. Its potential, however, is poorly exploited due to extensive catabolism. R-75231 inhibits transport of adenosine into endothelial cells, where it is catabolized, resulting in an elevation of interstitial adenosine concentrations. In 14 fetal lambs ( 3 to $5 \mathrm{~d}$ after surgery, gestational age $124.1 \pm 1.1 \mathrm{~d}$ ), seven fetuses were pretreated with $R$ $75231(0.1 \mathrm{mg} / \mathrm{kg}$ estimated fetal weight as a bolus injection in the inferior vena cava), whereas the other seven served as controls. After $1 \mathrm{~h}$ of severe asphyxia, induced by restriction of uterine blood flow, those fetuses treated with R-75231 showed a faster normalization of aortal pH and, in contrast to the control group, did not develop tachycardia. The percentage increase in myocardial blood flow during asphyxia, measured with radioactive microspheres, was significantly higher in the R-75231-treated group compared with the control group ( 437 and $284 \%$, respectively). In the control group, only three fetuses recovered and survived, whereas in the R-75231 group, all seven animals recovered after severe asphyxia. It is concluded that fetal lambs pretreated with R-75231 before the onset of severe asphyxia have an enhanced increase in myocardial blood flow during asphyxia, recover faster, and survive longer. (Pediatr Res 33: 185-189, 1993)
\end{abstract}

\section{Abbreviations}

Ado, adenosine

FHR, fetal heart rate

$\mathrm{Pa}$, arterial blood pressure

$P v$, venous blood pressure

MBF, myocardial blood flow

$[\mathrm{O} 2]$ a, arterial oxygen content

BE, base excess

It is well documented that lack of oxygen accelerates the catabolism of ATP in the myocardium, due to lack of rephosphorylation of ADP and AMP (1). This results in the formation of Ado. Because of its many interesting pharmacologic properties (coronary vasodilation, antiadrenergic effects, inhibition of plate-

Received February 24. 1992; accepted September 28, 1992.

Correspondence: Harmen H. de Haan. M.D., Department of Obstetrics and Gynecology, University Hospital, P.O. Box 5800. 6202 AZ Maastricht. The Netheriands. let and leukocyte activation) (2), the production of Ado can be regarded as a natural defense system. After $2 \mathrm{~h}$ of partial myocardial ischemia in dogs, ventricular function was improved by intracoronary administration of Ado (3).

Extensive catabolism of Ado in endothelial cells and the concomitant short half-life does not facilitate Ado therapy (4). Continuous infusions of high doses of Ado would be necessary. giving rise to systemic vasodilation and unwanted side effects in various organ systems. To avoid these problems, we pretreated fetal lambs with R-75231, a potent and specific Ado transportinhibiting drug with unique pharmacokinetic properties (5). During asphyxia, myocardial workload increases and Ado is released. Ado transport inhibition has two major advantages. First. R75231 will show an effect only if, and as long as, Ado is produced: second, the action will be restricted only to the area where Ado is produced. Thus, cardiac effects of Ado are enhanced, whereas side effects in other organs are avoided.

We hypothesized that an increased myocardial concentration of Ado during severe asphyxia leads to an enhanced MBF, better cardiac functioning during and after asphyxia, and an improvement in fetal survival. To test this hypothesis, we studied fetal lambs, pretreated with R-75231, during and after asphyxia. We measured cardiovascular parameters as FHR, Pa, Pv, and MBF.

\section{MATERIALS AND METHODS}

Surgery. Surgery was performed in 14 pregnant Dutch Texel sheep of known mating dates between 110 and $124 \mathrm{~d}$ of gestation $($ mean $\pm \mathrm{SEM}=120.5 \pm 1.0 \mathrm{~d}, 120.5 \pm 1.0 \mathrm{~d}$, term $=147 \mathrm{~d}$ ).

General anesthesia was induced with i.v. pentobarbital and maintained with $1 \%$ halothane in a $2: 1$ mixture of nitrous oxide and oxygen. Before surgery, the ewes received $1 \mathrm{~g}$ of ampicillin i.v. Under sterile conditions, a paramedian abdominal incision was made, and an inflatable balloon occluder was placed around the maternal common internal iliac artery. Fetal instrumentation involved insertion of catheters in the axillary and femoral artery, the tips advanced to the level of the brachiocephalic trunk and descending aorta, respectively. In addition, catheters were placed in the femoral vein with the tip advanced into the inferior vena cava, in the trachea, and in the amniotic cavity. Fine stainless steel wires (Cooner Sales Co., Chatsworth, CA) were placed over the dura of the parietal cortex for recording of the fetal electrocorticogram. A polyvinyl catheter was placed in the fourth ventricle to obtain cerebrospinal fluid. Electrodes were implanted s.c. at the level of the cardiac apex and at both forelegs for recording of the fetal ECG. Catheters and wires were exteriorized to the ewe's flank.

Ewes were housed in individual cages with free access to food and water and were allowed to recover from surgery for at least $3 \mathrm{~d}$ before the experiments were started. A continuous slow 
infusion $(1 \mathrm{~mL} / \mathrm{h})$ of heparine in saline $(10 \mathrm{U} / \mathrm{mL})$ was used to maintain patency of fetal arterial and venous catheters. Guidelines for care and use of animals as approved by the local Animal Medical Ethics Committee were followed.

Measurements. Fetal $\mathrm{Pa}$, fetal $\mathrm{Pv}$, tracheal pressure, and amniotic pressure were determined with the zero point at the level of the ewe's spine. These signals, together with the fetal ECG, the fetal electrocorticogram, and the FHR, derived from the pulsatile signal of the femoral artery, were fed into bioelectric amplifiers (Hewlett Packard 8800 series, Andover, MA), displayed on a monitor, recorded on an eight-channel strip chart recorder, stored on magnetic tape, and digitized and analyzed with a computer.

MBF was measured with radioactive microspheres with a diameter of $15 \mu \mathrm{m}$. In random order, one of four available microspheres $\left({ }^{141} \mathrm{Ce},{ }^{103} \mathrm{Ru},{ }^{95} \mathrm{Nb}\right.$, and ${ }^{113} \mathrm{Sn}$ ) was injected. Aggregation of the microspheres was prevented by adding $0.05 \%$ Tween 80 to the injection medium. After homogenization in an ultrasonic waterbath at $39^{\circ} \mathrm{C}$ (Bransonic 5200 , Soest, The Netherlands) for $20 \mathrm{~min}$, approximately $0.5 \times 10^{6}$ microspheres were stirred on a vortex agitator and infused over a period of $1 \mathrm{~min}$ into the inferior vena cava (6). Reference sampling $(1.80 \mathrm{~mL} /$ min) (Harvard Apparatus Ltd., Kent, England) was started from the brachiocephalic arch $30 \mathrm{~s}$ before infusion, continued during infusion, and stopped $1 \mathrm{~min}$ after infusion.

Blood gas values and $\mathrm{pH}$ from the fetal aortic arch were measured with an automated analyzer (AVL, Radiometer, Copenhagen, Denmark) and corrected for $39^{\circ} \mathrm{C}$. The percentage of saturation of $\mathrm{Hb}$ was measured (OSM2 Hemoximeter, Radiometer). [O2]a was calculated as follows:

$[\mathrm{O} 2] \mathrm{a}($ in $\mathrm{mM})=\mathrm{Hb}$ concentration $(\mathrm{mmol} / \mathrm{L})$

$\times \mathrm{Hb}$ oxygen saturation $(\% / 100)$.

Immediately after the microsphere injection, $2 \mathrm{~mL}$ of blood were withdrawn from the axillary artery and centrifuged $(3 \mathrm{~min}$ at $13000 \mathrm{rpm})$. Serum was frozen in liquid nitrogen and stored at $-73^{\circ} \mathrm{C}$. After all experiments had ended, serum lactate concentrations were determined in these samples.

Experiments. Gestational age during experiments varied between 113 and $129 \mathrm{~d}$ (mean \pm SEM $=124.1 \pm 1.1 \mathrm{~d}$ ). Baseline values for FHR, $\mathrm{Pa}$, and $\mathrm{Pv}$ were obtained during a control period of at least $2 \mathrm{~h}$. Fetal acid-base state was analyzed every 15 $\min$.

During the baseline period, MBF was determined. Fifteen min thereafter, seven of the 14 lambs received an i.v. bolus of R-75231 \{2-aminocarbonyl-N-(4-amino-2,6-dichlorophenyl)-4[5,5-bis(4-fluorophenyl)-pentyl]-1-piperazineacetamine $\}$ in a dose of $0.1 \mathrm{mg} / \mathrm{kg}$ estimated fetal weight. Estimation of fetal weight was performed during instrumentation.

Severe fetal asphyxia was induced by stepwise inflation of the balloon occluder around the maternal common internal iliac artery. During the occlusion period, every $15 \mathrm{~min}$ the aortal fetal acid-base state was determined. To maintain the fetus in a stable hemodynamic condition, uterine blood flow was gradually reduced over a period of 60 to $90 \mathrm{~min}$, until fetal [O2] a reached a value of approximately $30 \%$ of baseline level and/or the fetal $\mathrm{pH}$ had decreased to a value less than 7.15. This condition was considered the start of fetal asphyxia, and occlusion was kept at the same level for $1 \mathrm{~h}$. At the end of this period, MBF was remeasured. Thereupon, the uterine blood flow obstruction was discontinued by emptying the balloon occluder. MBF was determined again at 30 and $120 \mathrm{~min}$ after release of the occluder. Fetal recovery was monitored, and when the fetal condition did not improve 3 to $5 \mathrm{~h}$ after asphyxia, the fetal lambs were disconnected from registration and fetal $\mathrm{Pa}$ was checked regularly to determine survival interval. During the disconnected period, no blood gas analysis was performed. After $3 \mathrm{~d}$ of survival, a relaparotomy was performed. Under general anesthesia, fetal blood was replaced in vivo by Karnovsky's fixative solution (a mixture of $2.5 \%$ glutaraldehyde and $2.0 \%$ formaldehyde) to allow further histologic evaluation of the fetal brain. Subsequently, fetuses were removed and weighed, and correct catheter placement was confirmed at autopsy after $3 \mathrm{~d}$ or earlier in case of fetal demise.

Calculations and data analysis. FHR, $\mathrm{Pa}$, and $\mathrm{Pv}$, corrected for amniotic pressure, were averaged over 10 -s periods by computer.

For reasons of accuracy, MBF was calculated from the mean flow of three samples out of left ventricular base, middle, and apex of the fetal heart. The samples were weighed $( \pm 1 \mathrm{~g})$, put into test tubes, and additionally preserved in Karnovsky's fixative solution. Radioactivity in tissue and blood samples was measured with a gamma scintillation counter and sample changer system (analyzer model 45, Molsgaard Medical, Horsholm, Denmark). MBF was calculated with an ND680 programmable analyzer/ computer system (Nuclear Data GmbH, Frankfurt, Germany). All data are expressed as mean \pm SEM. For statistical analysis within groups, the Wilcoxon matched-pairs signed-ranks test was used, whereas differences between the R-75231-treated and the control group were tested with the two-tailed Mann-Whitney Utest. A $p$ value of $<0.05$ was considered significant. Linear regression analysis was performed for FHR and $\mathrm{pH}$ in the postocclusion period. Slopes of the lines of individual animals were compared by means of a two-tailed Mann-Whitney U test to determine differences between groups. The log rank test (7) was used to compare survival in both groups.

\section{RESULTS}

In Figure 1, the time course of mean [O2]a, $\mathrm{pH}$, and $\mathrm{BE}$ for both experimental groups is depicted. The magnitude of metabolic acidosis and BE decrease is comparable in both groups, although a small but a significant difference existed in [O2]a during the period of severe asphyxia (time $0-60 \mathrm{~min}$ ). In the R75231 -treated group, the [O2] a remained slightly higher. The $\mathrm{pH}$ after $1 \mathrm{~h}$ of severe asphyxia, however, was 6.99 and 7.06 for the R-75231-treated group and the control group, respectively $(p=0.08)$. Values below $-17.5 \mathrm{mmol} / \mathrm{L}$ were reached for the $\mathrm{BE}$ in both experimental groups. To analyze the speed of recovery, mean linear regression lines for $\mathrm{pH}$ against change in time in both groups were calculated over the postocclusion period, beginning at time $=60 \mathrm{~min}$, when the occluder was released. Comparison of the 14 individual slopes of these regression lines (mean slope $1.88 \pm 0.36, r=0.87$ and $0.76 \pm 0.39, r=0.89$ for the R-75231-treated and the control group, respectively) of these lines with a two-tailed Mann-Whitney $U$ test showed that the $\mathrm{pH}$ in the R-75231-treated group normalized faster $(p<0.05)$ toward baseline levels compared with the control group.

Time course of FHR, $\mathrm{Pa}$, and $\mathrm{Pv}$ is shown in Figure 2. Administration of R-75231 before the onset of occlusion did not induce any changes in either FHR, $\mathrm{Pa}$, or $\mathrm{Pv}$ in six of seven treated animals. In one animal, a transient bradycardia (from $145 \mathrm{bpm}$ to $110 \mathrm{bpm}$ ) of $15 \mathrm{~s}$ was observed, without simultaneous changes in $\mathrm{Pa}$ or $\mathrm{Pv}$. In the postocclusion phase, starting at time $=60 \mathrm{~min}$, linear regression lines for FHR against change in time in both groups were calculated. Comparison of the slopes of these lines [mean slope $-0.15 \pm 0.12(r=0.53)$ and $0.13 \pm 0.10$ $(r=0.62)$ for the R-75231-treated group and the control group, respectively] with a two-tailed Mann-Whitney $U$ test showed the development of a tachycardia (recovery period compared with baseline) in the control group versus the absence of this tachycardia in the $\mathrm{R}-75231$-treated group $(p<0.05)$. During the occlusion (approximately from time $=-75 \mathrm{~min}$ to time $=60$ $\mathrm{min}), \mathrm{Pa}$ in the control group was elevated compared with baseline levels (Wilcoxon matched-pairs signed-ranks test, $p<$ 0.05 ), whereas $\mathrm{Pa}$ remained unchanged in the $\mathrm{R}-75231$-treated group. At two moments in the occlusion period (time $=-75$ and $-45 \mathrm{~min}$ ), differences between groups reached significance. $\mathrm{Pv}$ remained unaltered in both groups during the entire experiment.

$\mathrm{MBF}$ was measured at four conditions in the experiment. At 

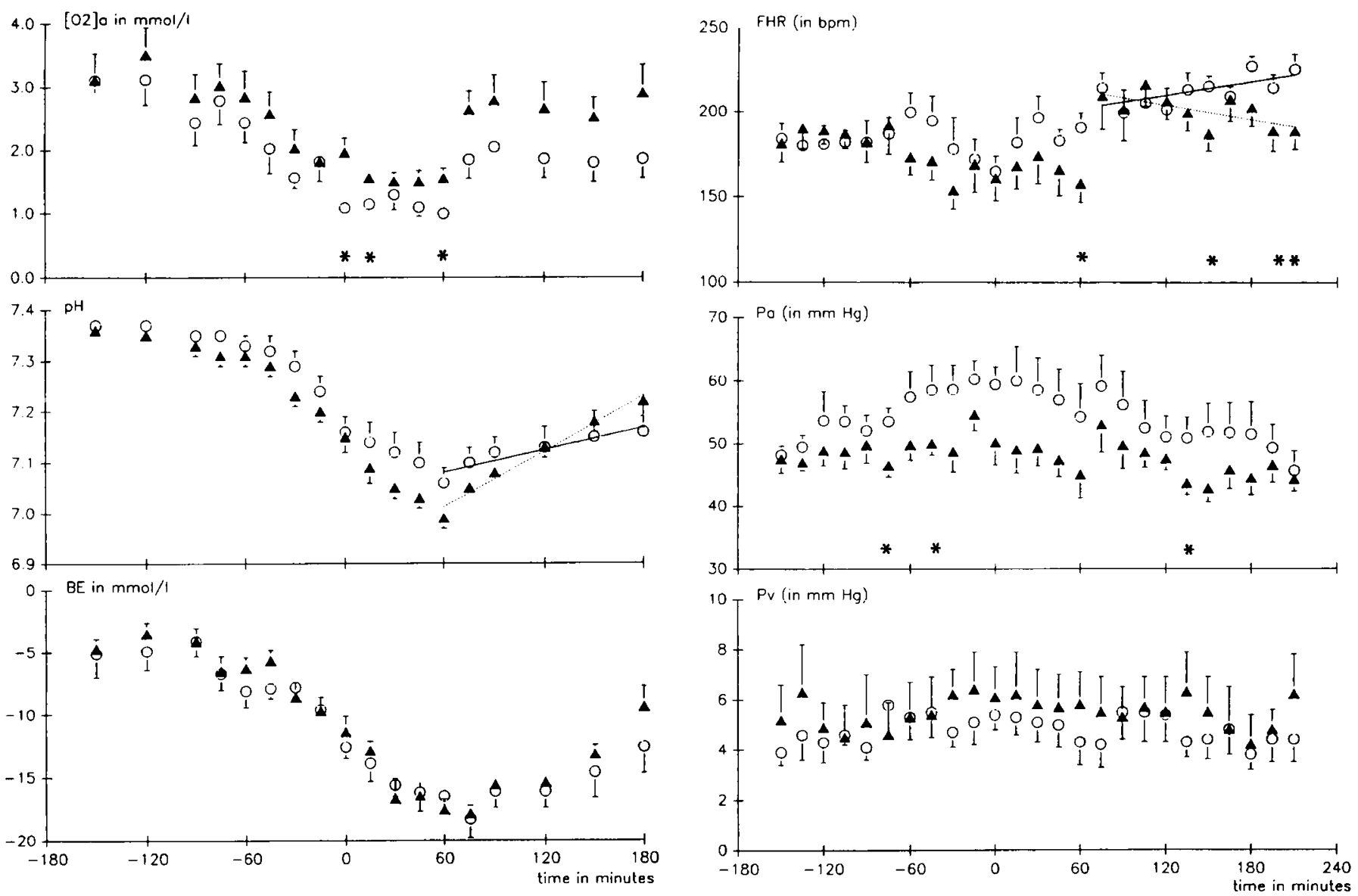

Fig. 1. Time course of [O2] $\mathrm{a}, \mathrm{pH}$, and $\mathrm{BE}$ (upper, middle. and lower panel, respectively), expressed as mean \pm SEM. Filled triangles represent the R-75231-treated group: open circles, the control group. Mean linear regression lines for the $\mathrm{R}-7523 \mathrm{I}$-treated group (dashed line) and the control group (solid line) in the postocclusion phase are drawn for $\mathrm{pH}$ against change in time. The slopes of these lines are significantly different (Mann-Whitney $\mathrm{U}$ test, $p<0.05$ ). Time -180 to $-100 \mathrm{~min}=$ baseline period; time -100 to $0 \mathrm{~min}=$ progressive reduction of uterine blood flow; time 0 to $60 \mathrm{~min}=1 \mathrm{~h}$ of severe asphyxia; time 60 to $180 \mathrm{~min}=$ postocclusion period. R-75231 was administered at time $=-120 \mathrm{~min}$. Differences between groups (two-tailed Mann-Whitney $\mathrm{U}$ test, $p<0.05$ ) are indicated with an asterisk.

these moments, serum lactate levels were determined as well. The individual MBF data of all 14 animals are shown in Figure 3 , whereas the means and percentage of increase are summarized in Table 1. During asphyxia, the percentage of increase in MBF was significantly higher in the R-75231-treated group than in the control group $(p<0.05)$. In contrast to the $\mathrm{R}-75231$-treated group, MBF remained significantly increased $(p<0.05)$ in the control group at $120 \mathrm{~min}$ after release of the occluder.

Table 2 summarizes the survival interval of all individual animals and the cause of fetal death. All animals of the treated group recovered well after asphyxia. Unfortunately, one ewe bit a fetal arterial catheter and the lamb bled to death $30 \mathrm{~h}$ after asphyxia. From a twin gestation, the instrumented (and treated) animal recovered, but a second (and untreated) lamb was not monitored. The treated lamb recovered well but died during parturition $22 \mathrm{~h}$ after the experiment. When the lambs were born, it was clear that the other lamb died much earlier (probably during the asphyxic period). This intrauterine death may have been the cause of preterm labor. Animals surviving longer then $72 \mathrm{~h}$ were killed for cerebral histology. Because of a logistical problem in the laboratory, one animal out of the control group was killed after only $24 \mathrm{~h}$. Survival in the R-75231-treated group was better than in the control group ( $\log$ rank test, $p<0.05$ ). In

Fig. 2. Time course of FHR, Pa, and Pv (upper, middle, and lower panel, respectively), expressed as mean \pm SEM. Filled triangles represent the R-75231-treated group; open circles, the control group. Mean linear regression lines for the R-75231-treated group (dashed line) and the control group (solid line) in the postocclusion phase are drawn for $\mathrm{pH}$ against change in time. The slopes of these lines are significantly different (Mann-Whitney $\mathrm{U}$ test, $p<0.05$ ). Time -180 to $-100 \mathrm{~min}=$ baseline period; time -100 to $0 \mathrm{~min}=$ progressive reduction of uterine blood flow; time 0 to $60 \mathrm{~min}=1-\mathrm{h}$ period of severe asphyxia; time 60 to 180 $\min =$ postocclusion period. $\mathrm{R}-75231$ was administered at time $=-120$ min. Differences between groups (two-tailed Mann-Whitney $\mathrm{U}$ test. $p<$ $0.05)$ are indicated with an asterisk.

this test, a correction has been made for the three animals described above.

\section{DISCUSSION}

Depletion of nucleotides has been regarded a major cause of irreversible damage and malfunctioning of the heart (8). High concentrations of Ado have been documented to protect against the damage from myocardial ischemia in isolated hearts from rats (9) and rabbits (10). Most convincing evidence for cardioprotection, however, has been gathered in a series of experiments in dogs, in which Ado has been infused in the coronary artery during the $1 \mathrm{st} \mathrm{h}$ of reperfusion after periods of regional ischemia lasting $40 \mathrm{~min}$ (11), $90 \mathrm{~min}$ (12), $2 \mathrm{~h} \mathrm{(3),} \mathrm{or} 3 \mathrm{~h} \mathrm{(13).}$ When compared with control animals, Ado-treated dogs had a much better functional recovery and a considerable reduction in infarct size. The benefit from Ado was lost when the ischemic period was extended to $3 \mathrm{~h}$. This limitation may be due to the extensive catabolism of Ado in endothelial cells and the rapid washout during reperfusion (4). Nucleoside transport inhibitors prevent the uptake of Ado into endothelial cells. In this way, deamination is inhibited, leading to elevated interstitial Ado levels. This mechanism was demonstrated after pretreatment 


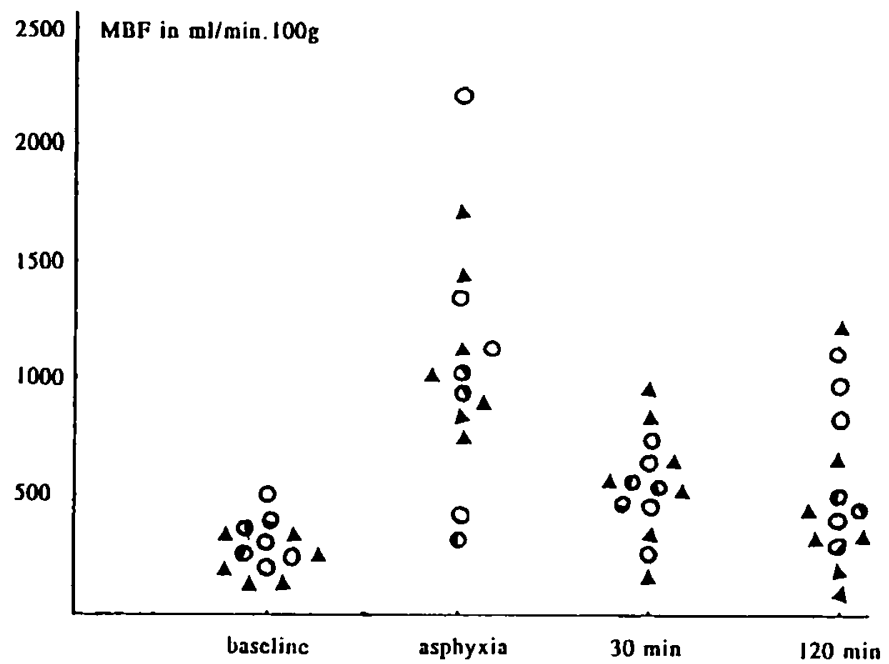

Fig. 3. MBF of all 14 animals at four moments in the experiment (baseline, after $1 \mathrm{~h}$ of severe asphyxia. and 30 and $120 \mathrm{~min}$ after release of the occluder). Filled triangles represent the R-75231-treated group: open circles, the control group without recovery $(n=4)$; and half-filled circles, the control group with recovery $(n=3)$.

with the nucleoside transport inhibitor mioflazine (14). Pharmacologic studies on R-75231 were even more promising (5). R75231 has recently been proposed as a highly effective concept for long-term preservation of donor hearts (15).

In the present study, restriction of uterine blood flow resulted in an increase of fetal $\mathrm{Pa}$ compared with baseline values (Wilcoxon matched-pairs signed-ranks test, $p<0.05$ ) in the control group (Fig. 2). The absence of this increase in blood pressure in the R-75231-treated group and the significant differences between both groups (at time $=-45,-75$, and $135 \mathrm{~min}$ ) may be explained by the vasodilatory effect of adenosine in fetal sheep (16). Levels of Ado are still expected to be elevated during the postocclusion phase, as R-75231 has a long duration of action (4). The differences between groups in FHR (at time $=150,195$, and $210 \mathrm{~min}$ ) may therefore be caused by the negative chronotropic activity of Ado (17) or by inhibition of the tachycardic effect of catecholamines (18). On the other hand, these FHR differences can also be explained by a better oxygenation and higher $\mathrm{pH}$ in the $\mathrm{R}-75231$-treated group, leading to normalization of myocardial performance.

During baseline measurements, MBF varies considerably between animals. This is in agreement with the literature $(19,20$, 21). MBF was measured at the nadir of asphyxia, at time $=60$ min. The [O2]a at this moment was significantly lower in the control group compared with the R-75231-treated group. Oxygen delivery to heart, brain, and adrenal glands is maintained by an increase in $\mathrm{MBF}$ when [O2] a decreases (19). Therefore, we expected the increase in MBF in the control group, i.e. the group with the lowest [O2]a, to be larger than the increase in the R- 75231-treated group. Although the absolute values of MBF were very similar in both groups during asphyxia, the percentage of increase in MBF was significantly higher in the R-75231-treated group (Table 1). As is shown in Figure 3, means of approximately $1000 \mathrm{~mL} \cdot \mathrm{min}^{-1} \cdot 100 \mathrm{~g}^{-1}$ do not equal the maximum coronary blood flow that can be reached. The larger percentage of increase in $\mathrm{MBF}$ in the R-75231-treated group may be the result of the coronary vasodilative effect of Ado (22). In the postasphyxial period, an enlarged diameter of vessels allows passage of microemboli, originating from hypoperfused tissues during asphyxia (23), and, as a result, coronary microembolization can be prevented. During the postocclusion period, MBF decreased in both groups compared with the asphyxic period. After $120 \mathrm{~min}$ in the postocclusion period, MBF in the control group remained elevated compared with baseline, whereas $\mathrm{MBF}$ in the treated group was normalizing and not elevated compared with baseline. We suggest that this difference is explained by an impaired oxygenation in the control group during this phase (mean [O2]a $\pm \mathrm{SEM}$ is $2.91 \pm 0.45$ and $1.87 \pm 0.30 \mathrm{mmol} / \mathrm{L}$ for the $\mathrm{R}-75231$ treated group and the control group, respectively, Mann-Whitney $\mathrm{U}$ test, $p<0.05$ ). Three of four nonsurvivors in the control group have an augmented MBF (as can be seen in Fig. 3), thus elevating mean $\mathrm{MBF}$ in the control group considerably.

Physiologic circulatory compensation during asphyxia, causing a preferential redistribution of blood, is available for a limited time only (24). Considering the magnitude and duration of asphyxia in the present study, inadequate recovery of four of seven animals (Table 2) in the second control group in the first $24 \mathrm{~h}$ after asphyxia is not surprising. A plausible explanation for this mortality is cardiovascular failure. After severe asphyxia, a transient tachycardia precedes progressive hypotension and death.

We suggest that pretreatment with the Ado transport-inhibiting drug R-75231 leads to an enhanced increase in MBF during severe fetal asphyxia. This leads to better myocardial performance after asphyxia, indicated by a faster normalization of $\mathrm{pH}$ and an absence of fetal tachycardia in the postocclusion period. Finally, this results in better survival.

As summarized elsewhere (5), nucleoside transport inhibition has been shown to be cardioprotective in a variety of experimental models and in different species. Because of the high specificity of nucleoside transport inhibition, its effects can be assumed to be solely due to the prolonged presence of Ado within the area where it is produced. In view of its many known activities (coronary vasodilation $=$ increased blood supply; antiadrenergic = lower demand; $\mathrm{Ca}^{2+}$-antagonist $=$ afterload reduction: antiarrythmic; inhibition of platelet aggregation = no thrombosis: inhibition of leukocyte activation = no damage from radicals or proteases), Ado can be regarded as a multipurpose drug that can tackle the many problems arising during myocardial hypoxemia and reperfusion. From the present experiment, it is not possible to define which of the activities of Ado is playing a major role. It is reasonable to assume that all of them acting in concert may contribute to the benefit observed.

Table 1. Fetal MBF and fetal lactate levels*

\begin{tabular}{lcccc}
\hline & Baseline & Asphyxia & $30 \mathrm{~min}$ & $120 \mathrm{~min}$ \\
\hline $\mathrm{R}-75231$ group & & & & \\
$\mathrm{MBF}\left(\mathrm{mL} \cdot \mathrm{min}^{-1} \cdot 100 \mathrm{~g}^{-1}\right)$ & $253 \pm 50$ & $1029 \pm 210 \dagger$ & $518 \pm 89 \dagger$ & $500 \pm 175$ \\
$\mathrm{MBF}(\%$ of baseline & 100 & $437 \pm 40 \dagger \ddagger$ & $236 \pm 57 \dagger$ & $188 \pm 50$ \\
Lactate $(\mathrm{mmol} / \mathrm{L})$ & $1.8 \pm 0.5$ & $14.7 \pm 0.6 \dagger$ & $14.4 \pm 0.6 \dagger$ & $11.5 \pm 0.7 \dagger$ \\
Control group & & & & \\
MBF $\left(\mathrm{mL} \cdot \mathrm{min}^{-1} \cdot 100 \mathrm{~g}^{-1}\right)$ & $347 \pm 44$ & $991 \pm 225 \dagger$ & $539 \pm 50 \dagger$ & $750 \pm 120 \dagger$ \\
MBF $(\%$ of baseline) & 100 & $284 \pm 60 \dagger \ddagger$ & $164 \pm 20 \dagger$ & $223 \pm 32 \dagger$ \\
Lactate $(\mathrm{mmol} / \mathrm{L})$ & $1.8 \pm 0.2$ & $12.6 \pm 1.5 \dagger$ & $12.0 \pm 1.4 \dagger$ & $12.8 \pm 1.8 \dagger$ \\
\hline
\end{tabular}

* Values are expressed as mean \pm SEM: $n=7$ for both groups. R- 75231 is administered after baseline measurements. MBF was determined after 1 -h severe asphyxia and 30 and $120 \mathrm{~min}$ after release of the occluder.

$+p<0.05$ (asphyxia. 30 or $120 \mathrm{~min}$ is baseline. Wilcoxon matched-pairs signed-ranks test).

$\ddagger p<0.05$ ( $\mathrm{R}-75231$ group is control group, two-tailed Mann-Whitney U test). 
Table 2. Fetal survival and cause of fetal death for both experimental gromps

\begin{tabular}{crl}
\hline Animal no. & $\begin{array}{r}\text { Survival } \\
\text { interval } \\
\text { (h) }\end{array}$ & \multicolumn{1}{c}{ Cause of fetal death } \\
\hline R-7523l group & & Killed for histology \\
1 & 72 & Killed for histology \\
2 & 72 & Killed for histology \\
3 & \pm 30 & Good fetal recovery, but catheter accident: \\
4 & 22 & Ewe in labor: fetus died during parturition \\
& 72 & Killed for histology \\
5 & 72 & Killed for histology \\
6 & & \\
7 & 10 & No recovery after asphyxia \\
Control group & 15 & No recovery after asphyxia \\
1 & 24 & Killed for histology \\
2 & 18 & No recovery after asphyxia \\
3 & 72 & Killed for histology \\
4 & 72 & Killed for histology \\
5 & 24 & No recovery after asphyxia \\
6 & & \\
7 &
\end{tabular}

In summary, pretreatment with the Ado transport-inhibiting drug $R-75231$ resulted in faster recovery and better survival after severe fetal asphyxia. Enhancement of the increase in MBF during asphyxia probably is one of the explanatory mechanisms. The actual working mechanism of Ado transport inhibition during severe asphyxia in fetal lambs remains to be elucidated.

\section{REFERENCES}

1. Jennings RB. Reimer KA. Hill ML. Mayer SE 1981 Total ischemia in dog hearts, in vitro. 1. Comparison of high energy phosphate production. utilization. and depletion. and of adenine nucleotide catabolism total ischemia in vitro vs. severe ischemia in vivo. Circ Res 49:892-900

2. Van Belle H 1985 Myocardial purines during ischemia, reperfusion and pharmacological protection. Mol Physiol 8:615-630

3. Babbitt DG. Virmani R. Forman MB 1989 Intracoronary adenosine administered after reperfusion limits vascular injury after prolonged ischemia in the canine model. Circulation 80:1388-1399

4. Van Belle H. Goossens F. Wynants J 1987 Formation and release of purine catabolites during hypoperfusion, anoxia, and ischemia. Am J Physiol 252:H886-H893

5. Van Belle H. Janssen PAJ 1991 Comparative pharmacology of nucleoside transport inhibitors. Nucleosides Nucleotides 10:975-982

6. Rudolph AM. Heymann MA 1967 The circulation of the fetus in utero. Circ Res 21:163-184
7. Pocock SJ 1983 Clinical trials, a practical approach. John Wiley \& Sons, Chichester, New York, p 224

8. Swain JL, Sabina RL, McHale PA. Greenfield JC. Holmes EW 1982 Prolonged myocardial nucleotide depletion after brief ischemia in the open-chest dog. Am J Physiol 242:H818-H826

9. Ledingham S, Katayama O, Lachno D, Patel N, Yacoub M 1990 Beneficial effect of adenosine during reperfusion following prolonged cardioplegic arrest. Cardiovasc Res 24:247-253

10. Bolling SF. Bies LE. Bove EL. Gallagher KP 1990 Augmenting intracellular adenosine improves myocardial recovery. J Thorac Cardiovasc Surg 99:469474

11. Velasco CE, Turner M, Cobb MA, Virmani R, Forman MB 1991 Myocardial reperfusion injury in the canine model after $40 \mathrm{~min}$ of ischemia: effect of intracoronary adenosine. Am Heart J 122:1561-1570

12. Pitarys CJ Virmani R, Vildibill HD. Jackson EK. Forman MB 1991 Reduction of myocardial reperfusion injury by intravenous adenosine administered during the early reperfusion period. Circulation 83:237-247

13. Babbitt DG, Virmani R Vildibill HD Norton ED, Forman MB 1990 Intracoronary adenosine administration during reperfusion following 3 hours of ischemia: effects on infarct size. ventricular function, and regional myocardial blood flow. Am Heart J 120:808-818

14. Van Belle H. Xhonneux R. Flameng W. Wijnants J 1986 Oral pretreatment with mioflazine completely changes the pattern and remarkably prolongs the accumulation of nucleosides in ischemic and reperfused myocardium Basic Res Cardiol 81:407-416

15. Flameng W. Sukehiro S, Möllhoff T, Van Belle H. Janssen PAJ 1992 A new concept of long-term donor heart preservation: nucleoside transport inhibition. J Heart Lung Transplant 10:990-998

16. Reid DL, Davidson SR, Phernetton TM, Rankin JHG 1990 Adenosine causes a biphasic response in the ovine fetal placental vasculature. J Dev Physiol 13:237-240

17. Clemo HF. Belardinelli L 1986 Effect of adenosine on atrioventricular conduction II: modulation of atrioventricular node transmission by adenosine in hypoxic isolated guinea pig hearts. Circ Res 59:437-446

18. Böhm M. Brückner R, Hackbarth I, Haubitz B. Linhart R. Meyer W. Schmidt B. Schmitz W. Scholz H 1984 Adenosine inhibition of catecholamine induced increase of force of contraction in guinea-pig atrial and ventricula heart preparations. Evidence against a cyclic AMP-and cycle GMP-dependent effect. J Pharmacol Exp Ther 230:483-492

19. Peeters LLH, Sheldon RE, Jones MD, Makowski EL, Meschia G 1979 Blood flow to fetal organs as a function of arterial oxygen content. Am J Obstet Gynecol 135:637-646

20. Bocking AD, Gagnon R, White SE, Homan J. Milne KM, Richardson BS 1988 Circulatory responses to prolonged hypoxemia in fetal sheep. Am J Obstet Gynecol 159:1418-1424

21. Reid DL. Parer JT, Williams K. Darr D, Phernetton TM, Rankin JHG 1991 Effects of severe reduction in maternal placental blood flow on blood flow distribution in the sheep fetus. J Dev Physiol 15:183-188

22. Berne RM 1980 The role of adenosine in the regulation of coronary blood flow. Circ Res 47:807-813

23. Hori M. Tamai J, Kitakaze M, Iwakura K, Gotoh K, Iwai K, Koretsune $Y$, Kagiva T, Kitabatake A. Kamada T 1989 Adenosine-induced hyperemia attenuates myocardial ischemia in coronary microembolization in dogs. Am J Physiol 257:H244-H251

24. Block BS. Schlafer DH. Wentworth RA. Kreitzer LA. Nathanielsz PW 1990 Intrauterine asphyxia and the breakdown of physiologic circulatory compensation in fetal sheep. Am J Obstet Gynecol 162:1325-1331 